研 究

MAによるMg-Ni-Yアモルファス合金の作製とパルス通電焼結によるパルク化

\author{
尾崎 公洋，小林 慶三，杉山 明，西尾 敏幸，松本 章宏 \\ 名古屋工業技術研究所，下 462-8510 名古屋市北区平手町 1-1.
}

\title{
Preparation of Amorphous Mg-Ni-Y Alloy by Mechanical Alloying and Pulsed Current Sintering
}

\author{
Kimihiro Ozaki, Keizo Kobayashi, Akira Sugiyama, Toshiyuki Nishio and Akihiro Matsumoto \\ National Industrial Research Institute of Nagoya, 1-1 Hiratechyo Kita-ku, Nagoya 452-8510.
}

Received January 13, 2000

\begin{abstract}
SYNOPSIS
Amorphous powder of $\mathrm{Mg}-\mathrm{Ni}-\mathrm{Y}$ system was prepared by mechanical alloying, and the amorphous bulk was produced by pulsed current sintering. The corrosion resistance was measured by polarization curve of the sintered amorphous specimen. After mechanically alloying of elementary powders for $400 \mathrm{~h}, \mathrm{Mg}_{80} \mathrm{Ni}_{15} \mathrm{Y}_{5}$ and $\mathrm{Mg}_{80} \mathrm{Ni}_{10} \mathrm{Y}_{5} \mathrm{~B}_{5}$ were obtained as powder but $\mathrm{Mg}_{80} \mathrm{Ni}_{5} \mathrm{Y}_{5} \mathrm{~B}_{10}$ are obtained like a fish scale. $\mathrm{Mg}_{80} \mathrm{Ni}_{15} \mathrm{Y}_{5}$ powder consisted of amorphous phase and $\mathrm{Mg}_{2} \mathrm{Ni}$ compound as the result by $\mathrm{XRD}$ and DSC measurements. However, $\mathrm{Mg}_{80} \mathrm{Ni}_{10} \mathrm{Y}_{5} \mathrm{~B}_{5}$ powder was almost amorphous phase. The bulk amorphous alloys were produced by pulsed current sintering of these amorphous powders at $423 \mathrm{~K}$ and $500 \mathrm{MPa}$. The pore ratio was about $0.6 \%$. The $\mathrm{Mg}$ amorphous alloys had higher corrosion potentials and lower corrosion current density than $\mathrm{AZ91D}$ alloy and pure $\mathrm{Mg}$, and their corrosion resistances of $\mathrm{Mg}$ alloy were improved.
\end{abstract}

\section{KEY WORDS}

amorphous powder, corrosion resistance, potential curve, bulk amorphous alloy, high pressure sintering

\section{1 緒言}

$\mathrm{Mg}$ 合金は軽量であるため比強度が高く,樹脂系材料に変わ る材料として注目されている。しかし，耐食性が低いや剛性 が低いという欠点がある。これらを補うため,アモルファス 合金やナノ結晶材料の作製が試みられている. $\mathrm{Mg}$ 系アモル ファス合金は, $\left.\mathrm{Mg}-\mathrm{Ca}^{1)}, \mathrm{Mg}-\mathrm{Ni}^{2}{ }^{2}, \mathrm{Mg}-\mathrm{Cu}^{3}\right), \mathrm{Mg}-\mathrm{Y}^{4)}$ などの二元 系合金およびこれらを基本に第三元素を添加した三元系につ いて，超急冷することによって作製できることが報告されて いる.また，高圧ダイキャスト法のや,クロースドシステムに おいてアトマイス粉を押し出し成形する方法のによってバル ク体の作製か試みられている.これらの手法はいずれも溶解 によって行われているが, Mgは溶解すると活性であり発火等 の危険が伴うため，霝囲気の制御が必要となり装置が複雑に なるという問題がある．また，大気中で溶解する場合には地 球温暖化規制ガスクである $\mathrm{SF}_{6}$ が不可欠である. 一方, 固体の $\mathrm{Mg}$ については発火等の危険はメカニカルアロイング(MA)な どの固相反応による非平衡化が有効な手段となる. 本研究で は，MA法を用いて固体の状態で Mg-Ni-Y系アモルファス合
金を作製し，これをパルス通電焼結することによってバルク 化するとともに，その耐食性を調べた。

\section{2 実験方法}

$\mathrm{Mg}$ (純度 99.9\%), Ni (純度 99.9\%), Y (純度 99.9\%), B (純 度 99\%)の素粉末を目的組成に配合しMAを行った.MAには 遊星型ボールミル(伊藤製作所製)を用い，冷風を送風するこ とによって MA 中の温度上昇を抑えてミリングを行った．ミ リングボールは直径 $10 \mathrm{~mm}$ のステンレス製であり, 容器は容 稳 $5.0 \times 10^{-3} \mathrm{~m}^{3}(500 \mathrm{ml})$ の $\mathrm{Cr}$ 鋼製を使用した。また，ボール重 量/粉末重量は20とし，回転数は 170r.p.m. とした. 容器には バルブを取り付け容器内の雾囲気を制御できる. 容器を約 $10 \mathrm{~Pa}$ まで真空引きした後Arガス (99.9\%)を100kPaまで導入するこ とを3回綝り返して残留酸素を低下させ，最終的に $100 \mathrm{kPa}$ の Arガス雲囲気とした. 作製した MA粉末の焼結にはパルス通 電焼結装置(住友石炭，現イスミテック製)を使用した。直径 $10 \mathrm{~mm}$ の円柱状および $6 \times 30 \mathrm{~mm}^{2}$ の矩形状の試料が作製できる 超硬型を用いて，最大加圧力 $500 \mathrm{MPa}$ で焼結した．温度条件 
は，目標温度の $20 \mathrm{~K}$ 低い温度まで $360 \mathrm{~s} て ゙$ 昇温し，その後目標 温度まで 120 sで上昇させ，目標温度で 300 s 保持した。 得ら れた粉末および嬅結体は光学顕微鏡, $X$ 線回折 (XRD), 示査 走查熱量測定(DSC), 走查型電子影微鏡(エネルギー分散型組 成分析, SEM-EDX) を用いて組織，構造，熱特性，組成分布 を調べた。焼結体の空孔率は画像処理によって求めた.また， 耐食性を調へるために， $1 \mathrm{M} の \mathrm{NaCl}$ 水溶液中で対極を白金と して分極曲線を求めた. 試料は直径 $10 \mathrm{~mm}$ の円柱状に作製し た試料を樹脂埋めし，バフ研磨したのち使用した。測定はポ テンショスタットを用いた動電位法で測定を行い, 電圧の走 查速度は $3 \mathrm{mV} / \mathrm{s}$ とした。

\subsection{MA粉末の合金化過程}

\section{3 実験結果および考案}

$\mathrm{Mg}_{80} \mathrm{Ni}_{15} \mathrm{Y}_{5}, \mathrm{Mg}_{80} \mathrm{Ni}_{10} \mathrm{Y}_{5} \mathrm{~B}_{5}$ および $\mathrm{Mg}_{80} \mathrm{Ni}_{5} \mathrm{Y}_{5} \mathrm{~B}_{10}$ につて $400 \mathrm{~h}$ ミリングを行った. $\mathrm{Mg}_{80} \mathrm{Ni}_{15} \mathrm{Y}_{5}$ および $\mathrm{Mg}_{80} \mathrm{Ni}_{10} \mathrm{Y}_{5} \mathrm{~B}_{5}$ は粉末状に なったが, $\mathrm{Mg}_{80} \mathrm{Ni}_{5} \mathrm{Y}_{5} \mathrm{~B}_{10}$ は粉末化せず解片状であった.これ は，B 量を增加させ $\mathrm{Ni}$ 量を減少させると金属 $\mathrm{Mg}$ の質量割合 が増加し， $\mathrm{Mg}$ の性質が強く現れるためと思われる．純 $\mathrm{Mg}$ を ミリングするとほとんどすべての量がボールおよび受内壁 に固着する. 添加元素が増加するとこの固着量が少なくなり 鱗片状になる．例えば, $\mathrm{Mg}-\mathrm{Fe}$ 系の MAでもこの現象を見る

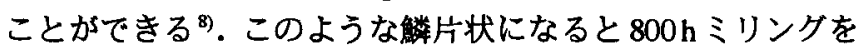
行っても形状に変化はなく,粉末を得ることはできなかった. またこの状態では合金化は進行しなかった. 400hのMAに よって粉末化した $\mathrm{Mg}_{80} \mathrm{Ni}_{15} \mathrm{Y}_{5}$ と $\mathrm{Mg}_{80} \mathrm{Ni}_{10} \mathrm{Y}_{5} \mathrm{~B}_{5}$ 合金の $\mathrm{X}$ 線回折 パターンを Fig.1に示す. $\mathrm{Mg}_{80} \mathrm{Ni}_{15} \mathrm{Y}_{5}$ の場合, ブロードな回折 ピークとともに $\mathrm{Mg}_{2} \mathrm{Ni}$ のピークも観察され，MAにより $\mathrm{Mg}_{2} \mathrm{Ni}$ が形成されていることがわかる.この金属間化合物は $300 \mathrm{~h} の$ ミリングで発生し， $400 \mathrm{~h}$ のミリングでも消失しない，一方， $\mathrm{Ni} \mathrm{B}$ て置換した $\mathrm{Mg}_{80} \mathrm{Ni}_{10} \mathrm{Y}_{5} \mathrm{~B}_{5}$ の場合，わずかに $\mathrm{Mg}_{2} \mathrm{Ni}$ のピー クが残るがほぼフロードな回折バターンとなっている。これ

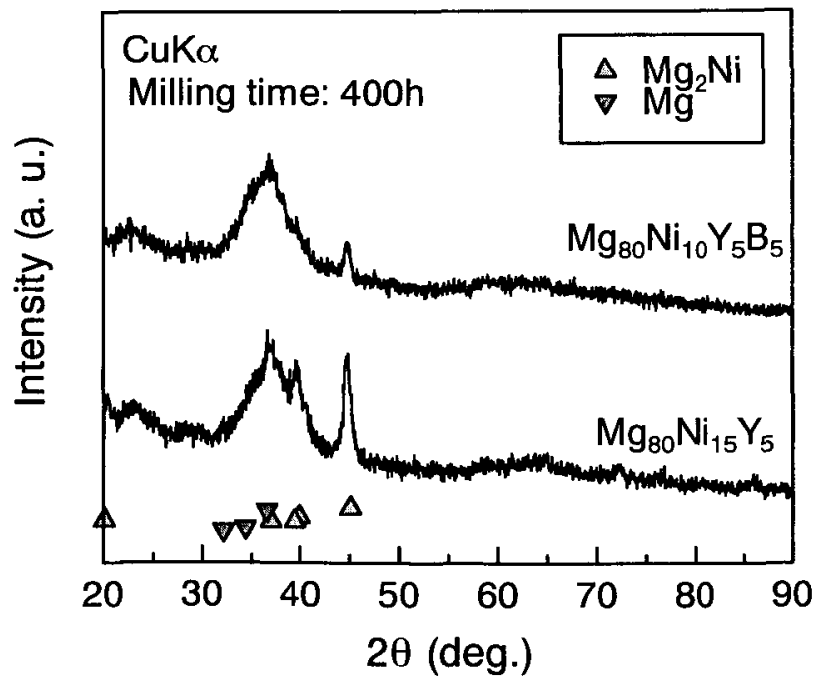

Fig.1 XRD patterns of mechanical alloyed $\mathrm{Mg}_{80} \mathrm{Ni}_{15} \mathrm{Y}_{5}$ and $\mathrm{Mg}_{80} \mathrm{Ni}_{10} \mathrm{Y}_{5} \mathrm{~B}_{5}$ powder milled for $400 \mathrm{~h}$.
は, Ni 量が少ないためと思われる.また，いずれの粉末にお いてもYおよびその化合物のピークは見られず，Yが $\mathrm{Mg}$ 固溶していることが示唆される. 平衡状態で $\mathrm{Y}$ は $\mathrm{Mg}$ に $3.4 \mathrm{at} \%$ しか固溶しないが，MAによって強制固溶しているものと思 われる.これらの粉末のDSC 曲線を調へた結果を Fig.2に示 す.いずれも約 $450 \mathrm{~K} て ゙$ 発熱が見られた.これは, 単ロール法 によって作製した $\mathrm{Mg}_{80} \mathrm{Ni}_{15} \mathrm{Y}_{5}$ アモルファスリボンの結晶化温 度とほぼ同じであるわ. Bの添加によって発熱温度は変化しな かった. $\mathrm{Mg}_{80} \mathrm{Ni}_{15} \mathrm{Y}_{5}$ と $\mathrm{Mg}_{80} \mathrm{Ni}_{10} \mathrm{Y}_{5} \mathrm{~B}_{5}$ においては $400 \mathrm{~h} の \mathrm{MA}$ 処 理によって，アモルファス粉末の作製が可能であることがわ かった. 特に $\mathrm{Mg}_{80} \mathrm{Ni}_{10} \mathrm{Y}_{5} \mathrm{~B}_{5}$ においては，ほぼアモルファス単 相になる. 発熱反応を起こした後の構造変化を調へるため, 熱処理した粉末のX線回折パターンを Fig.3に示す.いずれの 粉末においても，結晶化温度以上で熱処理すると金属 $\mathrm{Mg}$ の ピークが現れ，また $\mathrm{Mg}_{2} \mathrm{Ni}$ 化合物のピークが鋭くなっている。

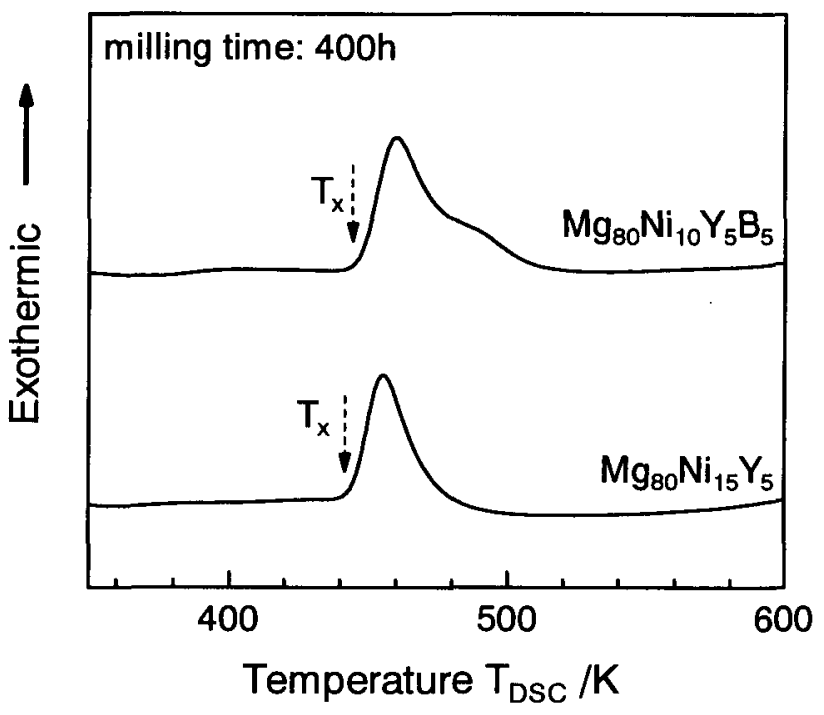

Fig.2 DSC curves of mechanical alloyed $\mathrm{Mg}_{80} \mathrm{Ni}_{15} \mathrm{Y}_{5}$ and $\mathrm{Mg}_{80} \mathrm{Ni}_{10} \mathrm{Y}_{5} \mathrm{~B}_{5}$ powder milled for $400 \mathrm{~h}$.

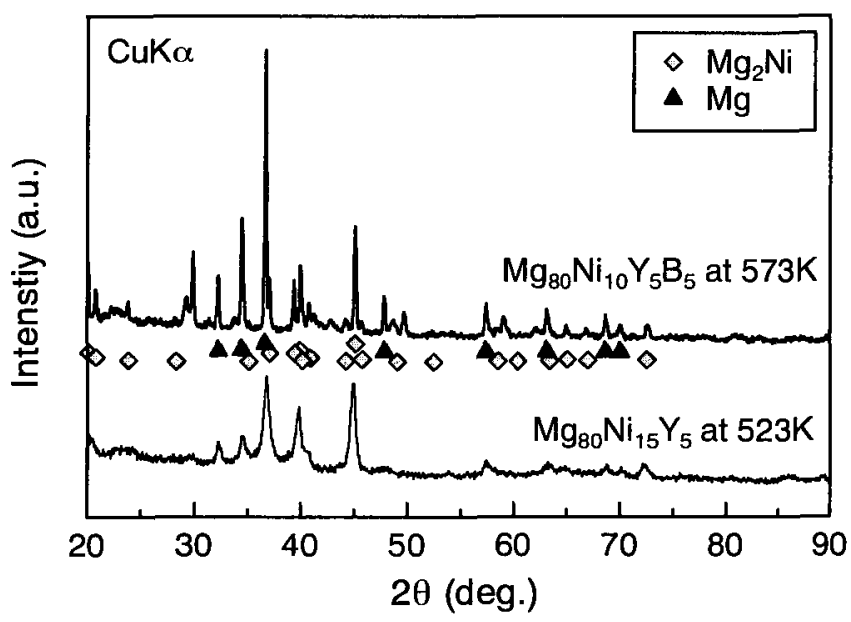

Fig.3 XRD patterns of mechanical alloyed powder after heat treatment over exothermic temperature. 


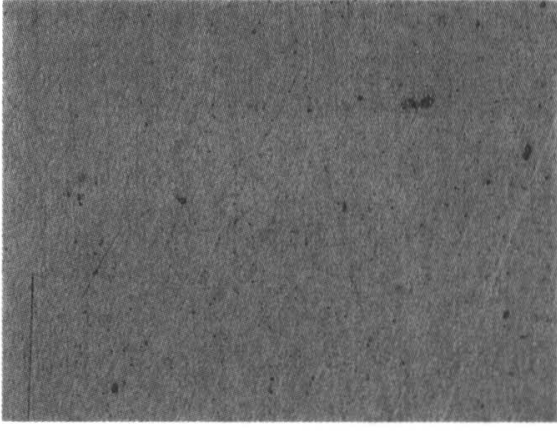

(a) at $423 \mathrm{~K}, 500 \mathrm{MPa}$

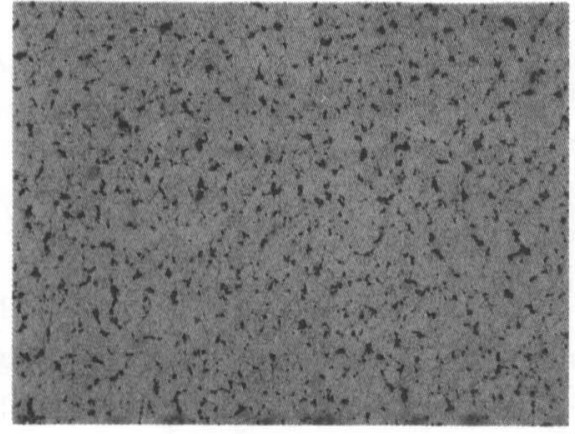

(b) at $423 \mathrm{~K}, 250 \mathrm{MPa}$

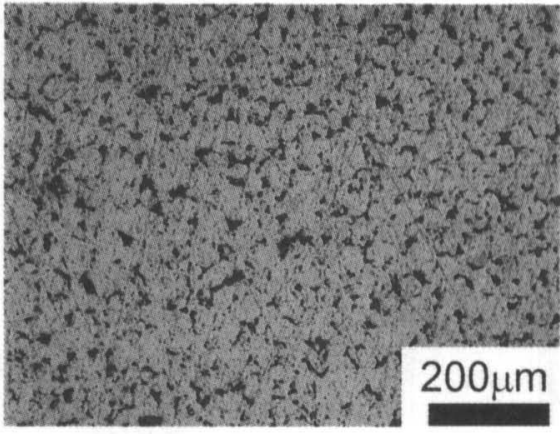

(c) at $373 \mathrm{~K}, 500 \mathrm{MPa}$

Fig.4 Optical microscope images of mechanically alloyed $\mathrm{Mg}_{80} \mathrm{Ni}_{15} \mathrm{Y}_{5}$ sintered by pulsed current.

このことから, アモルファスの結晶化によって $\mathrm{Mg}$ と $\mathrm{M}_{2} \mathrm{Ni}$ か 形成されることがわかる.

\subsection{MA 粉末の焼結}

アモルファス $\mathrm{Mg}_{80} \mathrm{Ni}_{15} \mathrm{Y}_{5}$ 粉末を結晶化温度以下で烤結温度 および加圧力を変化させ, 焼結密度(空孔率)におよぼす影響 を調べた.円筒超硬型を用いて作製した直径 $10 \mathrm{~mm}$ の試料の 光学顕微鏡像をFig.4に示す. 焼結温度が高く加圧力が高いほ ど空孔率が低くなっていることがわかる. 特に, 焼結温度 423 , 加圧力 $500 \mathrm{MPa}$ で焼結すると, 空孔率は約 $0.6 \%$ となり, $99 \%$ 以上の焼結密度となった. $\mathrm{Mg}_{80} \mathrm{Ni}_{10} \mathrm{Y}_{5} \mathrm{~B}_{5}$ においても同様の結果 が得られた. 焼結温度 $423 \mathrm{~K}$, 加圧力 $500 \mathrm{MPa}$ で作製した試料 のX線回折パターンを Fig.5に示す. 焼結の時の加熱によって $\mathrm{Mg}_{2} \mathrm{Ni}$ 化合物が析出し成長するが, アモルファス相が残存し ていることがわかる. 焼結体のビッカース硬度は $\mathrm{Mg}_{80} \mathrm{Ni}_{15} \mathrm{Y}_{5}$ が275Hv， $\mathrm{Mg}_{80} \mathrm{Ni}_{10} \mathrm{Y}_{5} \mathrm{~B}_{5}$ が255 Hvであつた. $\mathrm{Mg}_{80} \mathrm{Ni}_{15} \mathrm{Y}_{5}$ の方が わずかに硬くなっているのは, 金属間化合物による影響と思 われる. 直径 $10 \mathrm{~mm}$ の円盤状試料についての結果である. 超 硬型を異型状にすることにより, 種々の形状に成形すること

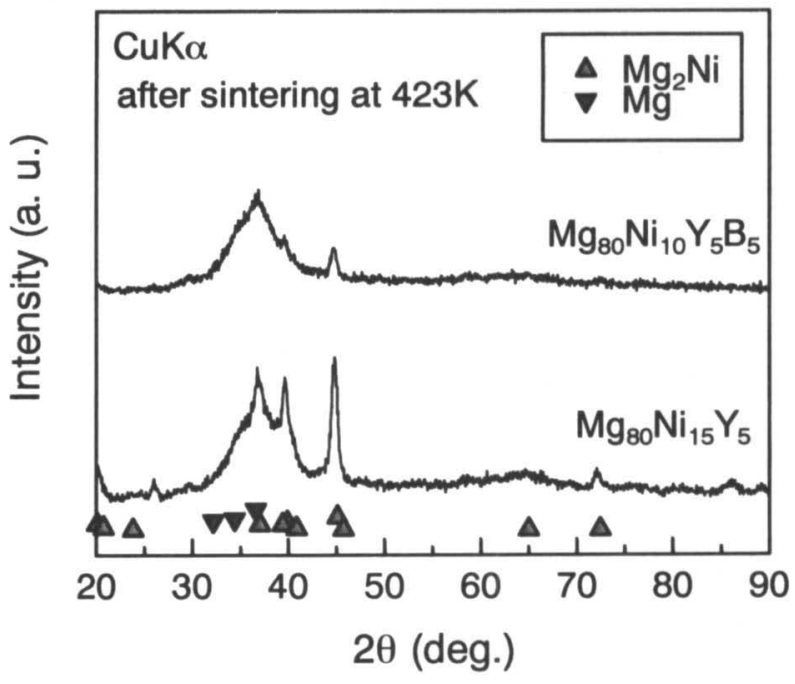

Fig.5 XRD patterns of $\mathrm{Mg}_{80} \mathrm{Ni}_{15} \mathrm{Y}_{5}$ and $\mathrm{Mg}_{80} \mathrm{Ni}_{10} \mathrm{Y}_{5} \mathrm{~B}_{5}$ alloys sintered at $423 \mathrm{~K}$.
が可能となる. Fig.6に焼結試料の一例を示す. いずれの試料 もアモルファス状態を保持しており, MA-パルス通電焼結法 によってアモルファスバルク材を作製することが可能となっ た.

\section{3 焼結体の耐食性}

烤結温度 $423 \mathrm{~K}$, 加圧力 $500 \mathrm{MPa}$ で作製した直径 $10 \mathrm{~mm}$ の焼 結体について，耐食性を評価するために分極曲線を求めた. 比較として純 $\mathrm{Mg}$ および $\mathrm{Mg}$ 合金として一般的な AZ91Dにつ いて測定した結果を Fig.7に示す. $\mathrm{Mg}_{80} \mathrm{Ni}_{15} \mathrm{Y}_{5}$ および $\mathrm{Mg}_{80} \mathrm{Ni}_{10} \mathrm{Y}_{5} \mathrm{~B}_{5}$ のいずれの場合も純 Mgあるいは AZ91D と比較して腐食電位 が高く腐食電流密度が低い.このことから, 本合金は純 $\mathrm{Mg} や$ AZ91D よりも耐食性が向上することがわかる. Mg は耐食性 の低い材料であるが, 合金化することによって純 $\mathrm{Mg}$ 量が減 少し耐食性が向上することが考えられる．このことは， AZ91D 合金が純 Mg よりも腐食電位が高くなる結果に現れて いる.しかし, Mg-Ni系9のように合金系および組成によって は純 $\mathrm{Mg}$ より耐食性が低下することが報告されており, 耐食 性が $\mathrm{Mg}$ 量のみに依存するわけではない.このような $\mathrm{Mg}-\mathrm{Ni}$ 系 に対して, 本アモルファス合金はYおよびBの添加によって, 耐食性が向上している．薄膜での実験結果で Mg-Y 系におい ては腐食電流密度が純 $\mathrm{Mg}$ より低下することが報告されてい る $^{10)}$ ことから, Yの添加によって Mg-Ni 系合金の耐食性も向 上するものと考えられる。

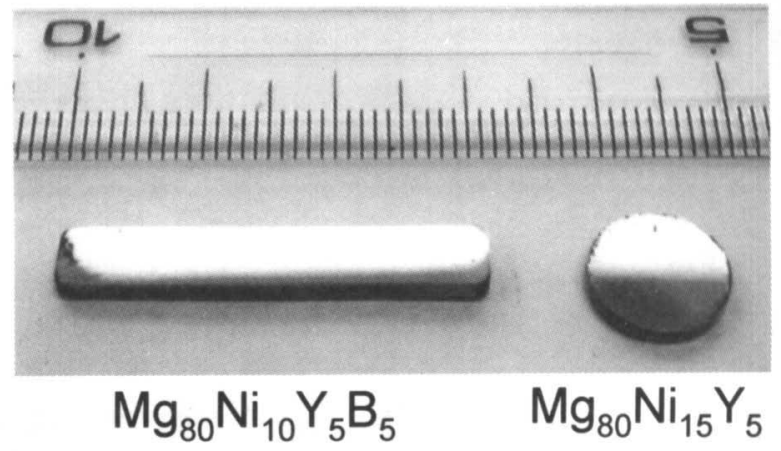

Fig.6 Mg amorphous alloys sintered by pulsed current. 


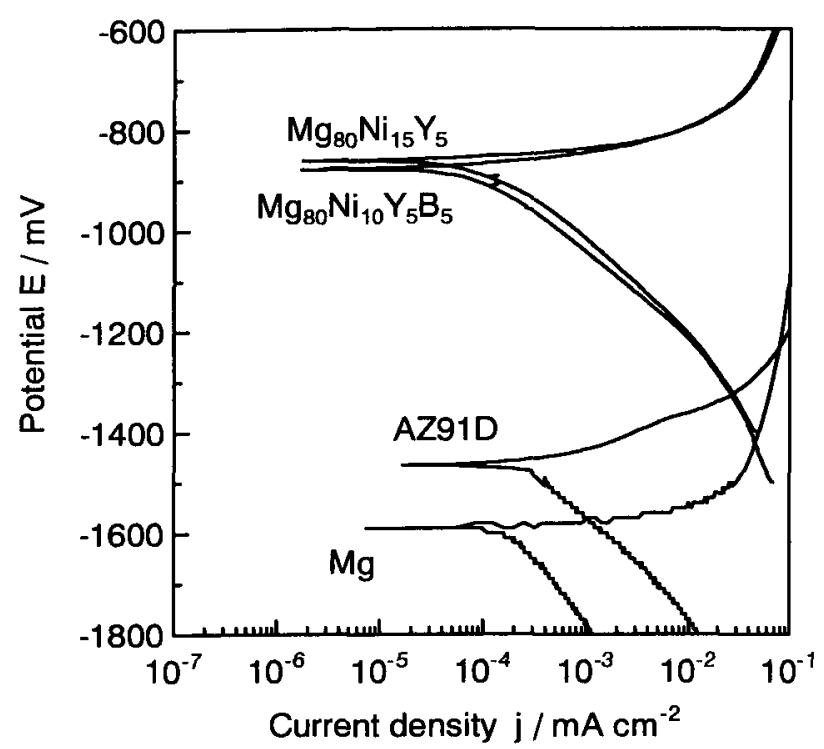

Fig.7 Polarization curves of sintered $\mathrm{Mg}$ amorphous alloys compared with AZ91D alloy and pure $\mathrm{Mg}$. Tests were conducted in $1 \mathrm{M} \mathrm{NaCl}$ at a scan rate $3 \mathrm{mV} / \mathrm{s}$.

\section{4 結 言}

メカニカルアロイングによって Mg-Ni-Y系のアモルファス 粉末を作製し，これをパルス通電焼結することによってバル ク体を作製した.また，バルク体の分極曲線を求め耐食性を 調べ，以下の結論を得た。

(1) $\mathrm{Mg}_{80} \mathrm{Ni}_{15} \mathrm{Y}_{5}, \mathrm{Mg}_{80} \mathrm{Ni}_{10} \mathrm{Y}_{5} \mathrm{~B}_{5}, \mathrm{Mg}_{80} \mathrm{Ni}_{5} \mathrm{Y}_{5} \mathrm{~B}_{10}$ を素粉末混合によっ て 400 時間 $\mathrm{MA}$ した結果， $\mathrm{Mg}_{80} \mathrm{Ni}_{15} \mathrm{Y}_{5}$ と $\mathrm{Mg}_{80} \mathrm{Ni}_{10} \mathrm{Y}_{5} \mathrm{~B}_{5}$ は粉 末であったか， $\mathrm{Mg}_{8 \mathrm{C}} \mathrm{Ni}_{5} \mathrm{Y}_{5} \mathrm{~B}_{10}$ は䚬片状となった。粉末に なった二種類の合金は，XRD およびDSCの結果から $\mathrm{Mg}_{2} \mathrm{Ni}$ 化合物が存在するものの, アモルファス相を有して いることが分かった.特に後者はほほアモルファス単相で あった。

(2) 粉末になった2種類の合金についてパルス通電焼結した結 果, $423 \mathrm{~K}, 500 \mathrm{MPa}$ の条件で作製すると空孔率約 $0.6 \%$ のバ
ルクアモルファスを作製することができた.このバルク体 は純 Mg やAZ91D合金よりも腐食電位が高く, 耐食性が 改善されていることがわかった。

\section{文献}

1) A.Kato, H.Horikir, A.Inoue and T.Masumoto: "Microstructure and Mechanical Properties of Bulk $\mathrm{Mg}_{70} \mathrm{Ca}_{10} \mathrm{Al}_{20}$ Alloys Produced by Extrusion of Atomized Amorphous Powders", Mater. Sci. Eng., A179/A180(1994)707-711.

2) S.G.Kim, A.Inoue and T.Masumoto: "High Mechanical Strengths of $\mathrm{Mg}-\mathrm{Ni}-\mathrm{Y}$ and $\mathrm{Mg}-\mathrm{Cu}-\mathrm{Y}$ Amorphous Alloys with Significant Supercooled Liquid Region", Mater. Trans. JIM, 31(1990)929934.

3) A.Kato, A.Inoue, H.Horikiri and T.Masumoto: "Consolidation and Their Mechanical Properties of Amorphous $\mathrm{Mg}_{87.5} \mathrm{Cu}_{5} \mathrm{Y}_{7.5}$ and $\mathrm{Mg}_{70} \mathrm{Ca}_{10} \mathrm{Al}_{20}$ Powders Produced by High Pressure Gas Atomization", Mater. Trans. JIM, 36(1995)977-981.

4) H.Horikiri, A.Kato, A.Inoue and T.Masumoto: "New Mg-based Amorphous Alloys in Mg-Y-misch Metal Systems", Mater. Sci. Eng., A179/A180(1994)702-706.

5) A.Inoue and T.Masumoto: "Mg-based Amorphous Alloys", Mater. Sci. Eng., A173(1993)1-8.

6) A.Kato, T.Suganuma, H.Horikiri, Y.Kawamura, A.Inoue and T.Masumoto: "Consolidation and Mechanical Properties of Atomized Mg-based Amorphous Powders", Mater. Sci. Eng., A179/A180(1994)112-117.

7) 気候変動枠組条的第 3 回締約国会議 (COP3) にて議決.

8) 小林, 尾崎, 杉山, 西尾: "Mg-Feのメカニカルアロイング による合成", 粉体および粉末治金, 46(1999)1068-1072.

9) 高谷松文: "マグネシウム合金の腐食技術",材料と環境, 48 (1999)476-483.

10) P.L.Miller, B.A.Shaw, R.G.Wendt and W.C.Moshier: "Assessing the Corrosion Resistance of Nonequilibrium Magnesium-Yttrium Alloys", Corrosion, 51(1995)922-931. 